\title{
PENGEMBANGAN MINAT PENANAMAN JAHE MENJADI USAHA MIKRO, KECIL DAN MENENGAH DESA GUMPANG KECAMATAN KARTASURA
}

\author{
Novita Trie A.P1), Dessy Ambarwati ${ }^{1)}$, Maya Oktavia1), Kiki Nurhalimah'), Nanda Ayu C. ${ }^{11}$, \\ Syaiful Anwar ${ }^{1)}$, Septiana Putri $\mathbf{H}^{1 \text { ), }}$ Melia Sari ${ }^{1)}$, Allivia Ayningtiyas ${ }^{1)}$, Yuli Chomsatu Samrotun ${ }^{1)}$
}

1)Program Studi Akuntansi , Fakultas Ekonomi, Universitas Islam Batik Surakarta, Jawa Tengah, Indonesia

Corresponding author : Novits Trie Ana Puspa

E-mail : novitatrieanap@gmail.com

Diterima 03 Januari 2021, Direvisi 12 Januari 2021, Disetujui 12 Januari 2021

\begin{abstract}
ABSTRAK
UMKM (Usaha Mikro, Kecil dan Menengah) merupakan usaha yang bebas hambatan dan tahan terhadap perubahan dan dinamika perubahan lingkungan dan global, di Indonesia, UMKM selain berperan dalam pertumbuhan pembangunan dan ekonomi, juga memiliki kontribusi yang penting dalam mengatasi masalah pengangguran. Tanaman jahe merupakan salah satu komoditas rempah yang banyak dibudidayakan dipekarangan rumah maupun lahan tertentu sehingga sering disebut sebagai tanaman TOGA. Tujuan kegiatan ini oleh mahasiswa secara bersama-sama dengan Warga Sadakan Kidul, RT 03 RW 02, Gumpang, Kartasura, Sukoharjo karena pada awal wabah covid 19 menyerang indonesia dan banyak rempah seperti jahe yang banyak dibutuhkan karena dapat meningkatkan imun dan kekebalan tubuh sehingga, harga jahe melonjak tinggi dan sulit didapatkan. Kegiatan ini dilakukan dengan sosialisasi, pelatihan, dan pelatihan sarana dan prasarana. Hasil dari kegiatan ini adalah bahwa potensi yang ada telah dilakukan atau di kelola dengan baik oleh masyarakat Desa Sadakan Kidul, RT 03 RW 02, Gumpang, Kartasura, Sukoharjo. Dengan pengelolaan tersebut secara tidak langsung dapat menumbuhkan perekonomian desa dan bisa mengembangkan UMKM per warga dan bisa mengurangi pengangguran di antara masyarakat Indonesia.
\end{abstract}

Kata Kunci : UMKM; jahe; masyarakat

\begin{abstract}
UMKM is a business that is barrier-free and resistant to changes and dynamics of environmental and global changes. In Indonesia, in addition to playing a role in development and economic growth, MSMEs also have an important contribution in overcoming the problem of unemployment. The ginger plant is one of the spice commodities that is widely cultivated in the garden of houses and certain fields, so it is often referred to as a TOGA plant. The purpose of this activity by students together with the residents of Segang Kidul, RT 03 RW 02, Gumpang, Kartasura, Sukoharjo because at the beginning of the Covid 19 outbreak attacked Indonesia and many spices such as ginger were needed because they could increase immunity and so, the price ginger is soaring and hard to come by. This activity is carried out by socialization, training, and training on facilities and infrastructure. The result of this activity is that the existing potentials have been carried out or managed well by the people of the Village of Segang Kidul, RT 03 RW 02, Gumpang, Kartasura, Sukoharjo. This management can indirectly grow the village economy and develop MSMEs per citizen and reduce unemployment among Indonesians.
\end{abstract}

Keywords: UMKM; ginger; society

\section{PENDAHULUAN}

Kabupaten kabupaten terkeciljo merupakan Tengah, Secara geografis, terletak diantara Bagian ujung timur 110.570 BT, Bagian Ujung Sebelah Barat 110.420 BT, Bagian Ujung Sebelah Utara 7.320 LS, Bagian Ujung Sebelah Utara 7.490 LS. Dengan luas $46.666 \mathrm{~km} 2$ atau
$1.43 \%$ luas wilayah Propinsi Jawa Tengah. Kabupaten Sukoharjo memiliki batas-batas wilayah administrasi sebagai berikut : Sebelah Utara Kota Surakarta dan Kabupaten Karanganyar, Sebalah Selatan Kabupaten Gunung Kidul (DIY) dan Kabupaten Wonogiri, Sebelah Barat Kabupaten Karangayar, Sebelah 
Timur : Kabupaten Boyolali dan Kabupaten Klaten.

Kabupaten Sukoharjo terdiri dari 12 kecamatan, 17 kelurahan, dan 150 desa. Kecamatan Kartasura sebagai salah satu kecamatan yang di terletak di Kabupaten Sukoharjo yang dikenal luas oleh masyarakat Kota Solo dan sekitarnya. Salah satunya di kelurahan Gumpang banyak pelaku UMKM yang cukup membangun perekonomian dan mengurangi pengangguran didesa gumpang.

Menurut Hidayat (Dahlan, 2017) Pentingnya pengembangan dan pemberdayaan usaha mikro, kecil dan menengah (UMKM) sudah saatnya dikedepankan karena UMKM merupakan usaha yang bebas hambatan dan tahan terhadap perubahan dan dinamika perubahan lingkungan dan global, di Indonesia, UMKM selain berperan dalam pertumbuhan pembangunan dan ekonomi, juga memiliki kontribusi yang penting dalam mengatasi masalah pengangguran. Pemberdayaan Usaha Kecil, dan Menengah ditengah arus globalisasi dan tingginya persaingan membuat UKM harus mampu menghadapi tantangan global, seperti meningkatkan inovasi produk dan jasa, pengembangan sumber daya manusia dan teknologi, serta perluasan area pemasaran (Rahmadani, Hakim, \& Setiawati, 2019). Usaha kecil dan menengah sangat berpengaruh terhadap perekonomian negara, bahkan lebih daripada separuh penduduk Indonesia berpenghasilan dari sektor ini (Ukkas, 2017).

Salah satu UMKM di Desa Gumpang yaitu Budidaya Jahe. Budidaya merupakan kegiatan yang sudah terencana dan dilakukan dalam suatu area atau lahan untuk diambil manfaatnya. Budidaya jahe dipilih karena pada saat wabah Covid menyerang Indonesia harga jahe melonjak tinggi sehingga bapak Saidi selaku ketua RT dari Desa Sadakan Kidul, RT 03 RW 02, Gumpang Kartasura, Sukoharjo terpikirkan untuk budidaya jahe sendiri sekaligus mengajak warga setempat untuk gotong royong budidaya jahe agar mereka bisa budidaya sendiri dirumah.

Tanaman jahe merupakan salah satu komoditas rempah yang banyak dibudidayakan dipekarangan rumah maupun lahan tertentu sehingga sering disebut sebagai tanaman TOGA (Nurahman, Kurniawati, \& Novianty, 2020). Jahe merupakan bahan baku terbesar kedua setelah temulawak, kebutuhan sebagai bahan baku dan bahan dasar dari jahe setiap tahun mengalami kenaikan yang signifikan (Mussafi, Nugraheni, \& Malahayati, 2017). Menurut Karama et al dalam (Lestari, Astuti, Malik, \& Kardiyanto, 2018) pemanfaatan lahan secara intensif untuk tanaman semusim sepanjang tahun perlu diimbangi dengan pembarian pupuk organik yang memadai untuk mempertahankan kandungan bahan organik tanah.

\section{METODE}

Penelitian dilaksanakan di Desa Gumpang Kecamatan Kartasura Kabupaten Sukoharjo pada tanggal 20-31 oktober 2020.

Bentuk kegiatan yang didanai bagi mahasiswa dan dosen pembimbing dilakukan dalam bentuk sosialisasi, penambahan prasarana pembibitan.

Tabel 1. Kegiatan yang dilaksanakan

\begin{tabular}{llrl}
\hline Kegiatan & Tujuan & Luaran \\
\hline Sosialisasi & Dilakukan oleh & Program \\
& warga RT 03/RW & kerja \\
& 02 & \\
\hline Pelatihan & Warga & RT & Media \\
& 03/RW 02 & informasi \\
& sadakan kidul, & untuk \\
& gumpang & promosi \\
& kartasura, agar & pembibitan \\
& sukoharjo ahe \\
& memanfaatkan & kedepannya \\
& kas rt untuk & \\
& pengembangan & \\
& UMKM dan & \\
& memperbaiki & \\
& perekonomian di & \\
desa tersebut & \\
\hline Perbaikan & Perbaikan media & Polibag \\
sarana & pembibitan jahe & sebagai \\
prasarana & & media \\
\hline Evaluasi & Kesesuaian & Adanya \\
& perencanaan & laporan hasil \\
& dan realisasi dan & kegiatan \\
& keberlanjutan & \\
\hline
\end{tabular}

Metode ini dilakukan oleh mahasiswa secara bersama-sama dengan Warga Sadakan Kidul, RT 03 RW 02, Gumpang, Kartasura, Sukoharjo. Kegiatan ini muncul karena pada awal wabah covid 19 menyerang indonesia dan banyak rempah seperti jahe yang banyak dibutuhkan karena dapat meningkatkan imun dan kekebalan tubuh sehingga, harga jahe melonjak tinggi dan sulit didapatkan. Maka dari itu Bapak Saidi selaku ketua RT Desa Sadakan Kidul RT 03 RW 02, Gumpang, Kartasura mengajak warganya untuk gotong royong budidaya jahe dan dapat menerapkannya dirumah supaya membangun perekonomian warganya. Tujuan dari kegiatan ini adalah membantu potensi ekonomi yang dapat dikembangkan dengan dukungan dari warga 
setempat. Kegiatan ini dilaksanakan di Desa Gumpang Kecamatan Kartasura atau di lokasi kegiatan tersebut dilaksanakan.

\section{HASIL DAN PEMBAHASAN \\ Sosialisasi}

Kegiatan ini dimulai dengan melakukan sosialisasi pada tanggal 27 Oktober 2020 dengan menggundang warga Desa Sadakan Kidul, RT 03 RW 02, Gumpang, Kartasura untuk pelaksanaan sosialisasi pengembangan UMKM dengan memfokuskan keadaan yang ada pada rencana awal tentang pembibitan jahe. Sosialisasi ini dilakukan agar warga lebih mengenal baik tentang UMKM, mengatur pola keuangan di dalam usaha sendiri, lebih mengetahui apa minat dan ketertarikan dalam memulai usaha dan bisa mengetahui peluang dalam memanfaatkan era new normal seperti saat ini ataupun saat semua sudah kembali normal.

Pada gambar 1 dijelaskan bahwa sosialisasi dilakukan pada warga Sadakan Kidul, RT 03 RW 02, Gumpang, Kartasura, agar lebih memahami dan berpartisipasi aktif dalam membangun perekonomian dan potensi desa tersebut. Kemudian gambar 2 menunjukkan bahwa kami melakukan tinjauan atas penanaman jahe bersama dengan Bapak Saidi selaku Ketua RT Desa Sadakan Kidul RT 03 RW 02, Gumpang, Kartasura.

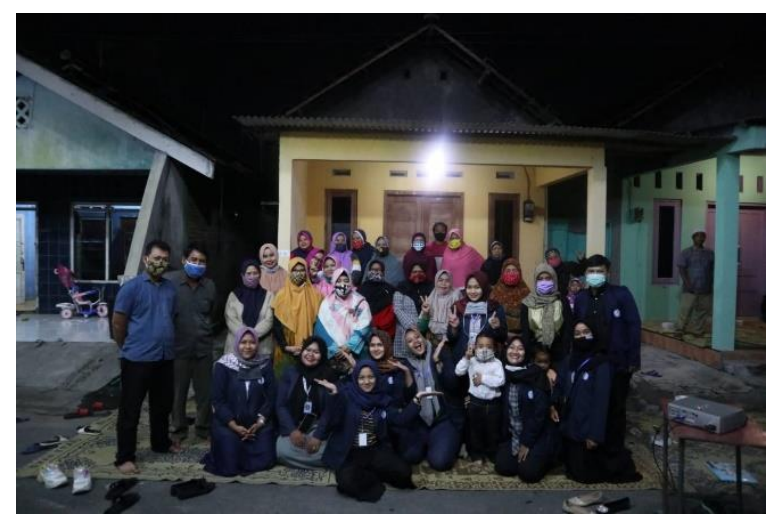

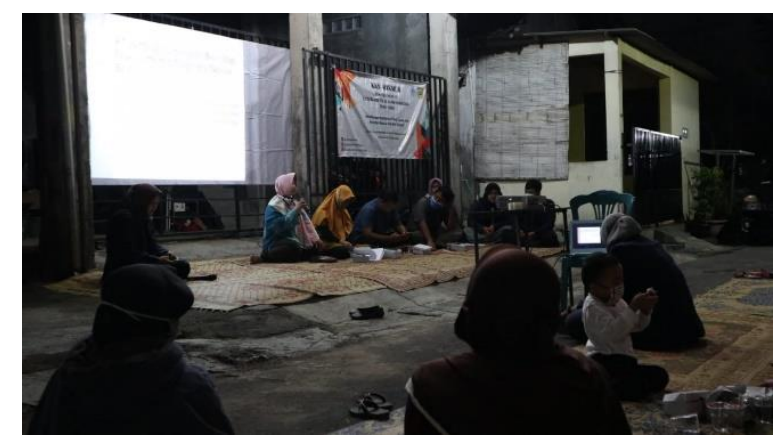

Gambar 1. Kegiatan Sosialisasi

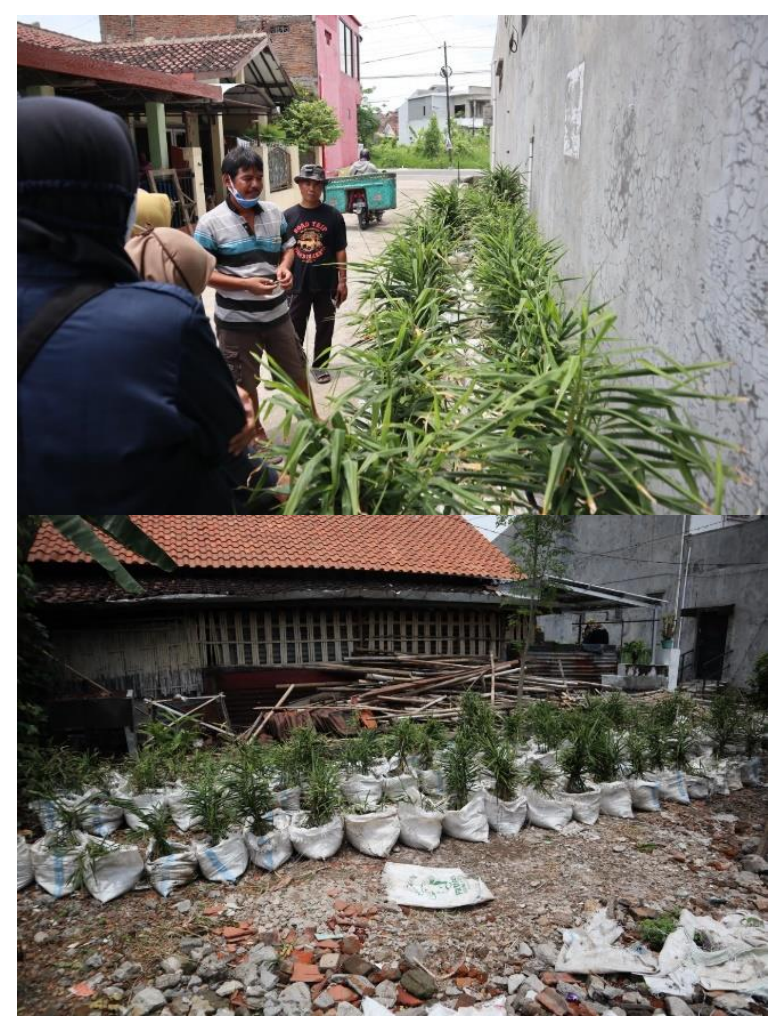

Gambar 2. Kegiatan Peninjauan penanaman jahe

\section{Pelatihan}

Pelatihan lebih difokuskan pada warga Sadakan Kidul, RT 03 RW 02, Gumpang, Kartasura dalam memanfaatkan media informasi yang digunakan dalam promosi seperti WhatsApp, Instagram, Twitter, Facebook dengan tampilan dan kata kata yang menarik perhatian konsumen.

\section{Pengadaan Sarana dan Prasarana}

Karena penanaman jahe sudah dilaksanakan oleh warga Sadakan Kidul, RT 03 RW 02, Gumpang, Kartasura dan sudah berlangsung selama kurang lebih 6 bulan, Tim mendiskusikan mengenai hal yang diperlukan 
selain bibit jahe dan pupuk. Tanggapan dari Bapak Saidi yaitu warga sendiri kekurangan mengenai media tanam yang di pakai selanjutnya setelah pembibitan jahe telah tumbuh. Kemudian pada tanggal 30 Oktober 2020, Tim membeli beberapa media tanam yang akan di serahkan ke pihak Desa Sadakan Kidul RT 03 RW 02, Gumpang, Kartasura agar bisa dimanfaatkan untuk media tanam pengembahan jahe agar bisa menambah jumlah hasil tanam dari jahe tersebut.

\section{SIMPULAN DAN SARAN}

Dari hasil yang telah dilaksanakan dalam Kuliah Kerja Nyata atas bimbingan dan penjelasan dari warga Desa Sadakan Kidul, Gumpang, Kartasura dalam pengembangan potensi UMKM untuk penanaman jahe yang dilakukan oleh Dosen Pembimbing Lapangan sebanyak 2 orang dan tim KKN Program Studi Akuntansi Fakultas Ekonomi Universitas Islam Batik Surakarta yang dimulai dari tanggal 20 Oktober hingga 31 Oktober 2020 dapat diberi kesimpulan bahwa potensi yang ada telah dilakukan atau di kelola dengan baik oleh masyarakat Desa Sadakan Kidul, RT 03 RW 02, Gumpang, Kartasura, Sukoharjo. Dengan pengelolaan tersebut secara tidak langsung dapat menumbuhkan perekonomian desa dan bisa mengembangkan UMKM per warga dan bisa mengurangi pengangguran di antara masyarakat Indonesia. Hal ini sejalan dengan

pentingnya pengembangan dan pemberdayaan usaha mikro, kecil dan menengah (UMKM) sudah saatnya dikedepankan karena UMKM merupakan usaha yang bebas hambatan dan tahan terhadap perubahan dan dinamika perubahan lingkungan dan global, di Indonesia, UMKM selain berperan dalam pertumbuhan pembangunan dan ekonomi, juga memiliki kontribusi yang penting dalam mengatasi masalah pengangguran. (Dahlan, 2017)

Jahe merupakan bahan baku terbesar kedua setelah temulawak, kebutuhan sebagai bahan baku dan bahan dasar dari jahe setiap tahun mengalami kenaikan yang signifikan (Mussafi, Nugraheni, \& Malahayati, 2017)

\section{DAFTAR RUJUKAN}

Dahlan, M. (2017). PERAN PENGABDIAN PADA MASYARAKAT DALAM PEMBERDAYAAN USAHA MIKRO, KECIL DAN MENENGAH (UMKM) . Jurnal Pengabdian Kepada Masyarakat, 81-86.
Lestari, S., Astuti, Y., Malik, R. J., \& Kardiyanto, E. (2018). Keragaman Pertumbuhan Tanaman Jahe Merah (Zingiber officinale Rosc.) pada kondisi Cekaman Kekeringan di Provinsi Banten. AGROVIGOR, 9-14.

Mussafi, N. S., Nugraheni, I., \& Malahayati. (2017). Rekayasa Jahe Merah Pada Lahan Kering Girisuko Gunung Kidul Untuk Optimalisasi Kelompok Tani Wanita Sukosari Guna Meningkatkan Perekonomian Keluarga Miskin. Jurnal Bakti Saintek, 1-8.

Nurahman, I. S., Kurniawati, T., \& Novianty, A. (2020). PEMBERIAN TRICHOKOMPOS TERHADAP PERTUMBUHAN DAN PRODUKSI TANAMAN JAHE MERAH (Zingiber officinale var. Rubrum) DI KELOMPOK WANITA TANI "LINGKUNG GUNUNG". ABDIMAS GALUH, 129-234.

Rahmadani, A., Hakim, L., \& Setiawati, B. (2019). PENGARUH PEMBERDAYAAN USAHA KECIL DAN MENENGAH TERHADAP PEMBANGUNAN EKONOMI MASYARAKAT KECAMATAN WARA KOTA PALOPO. Jurnal Administrasi Publik, 244-261.

Ukkas, I. (2017). STRATEGI DAN UPAYA PENGEMBANGAN USAHA MIKRO KECIL MENENGAH (UMKM). JURNAL PENGABDIAN KEPADA MASYARAKAT, 22-25. 